Плодоводство и виноградарство Юга России № 60(6), 2019 г.

УДК 634.8:681

DOI 10.30679/2219-5335-2019-6-60-124-135

СИСТЕМНАЯ АРХИТЕКТУРА КОМПЬЮТЕРНОЙ МОДЕЛИ УПРАВЛЕНИЯ АМПЕЛОЦЕНОЗАМИ ${ }^{1}$

Попова Дарья Викторовна директор e-mail: ilina.daria@gmail.com

ООО «Малое инновачионное предприятие «АмпелоИнформПродукт»

Ильина Ирина Анатольевна д-р техн. наук, профессор заместитель директора по науке e-mail: kubansad@kubannet.ru

Петров Валерий Семёнович д-р с.-х. наук заведующий функциональным научным центром «Виноградарство и виноделие» e-mail: petrov_53@mail.ru

Соколова Виктория Викторовна канд. с-х. наук, заведующая научнообразовательным сектором e-mail: KudryshovaVV@yandex.ru

Федеральное государственное бюджетное научное учреждение «Северо-Кавказский федеральный научный иентр садоводства, виноградарства, виноделия», Краснодар, Россия

Статья раскрывает вопросы, связанные с разработкой компьютерной программы для создания и управления продукционным потенциалом ампелоценозов. Данная программа
UDC 634.8:681

DOI 10.30679/2219-5335-2019-6-60-124-135

\section{SYSTEM ARCHITECTURE OF COMPUTER MODEL FOR AMPELOCENOSES MANAGEMENT}

\author{
Popova Daria Viktorovna \\ Director \\ e-mail: ilina.daria@gmail.com \\ «Small Innovative Enterprise \\ «AmpeloInformProdukt» LLC \\ Ilina Irina Anatolyevna \\ Dr. Tech. Sci., Professor \\ Deputy Director for Science \\ e-mail: kubansad@kubannet.ru
}

Petrov Valeriy Semionovich

Dr. Agr. Sci.

Head of the Functional

Scientific Center

of «Viticulture and Winemaking»

e-mail: petrov_53@mail.ru

Sokolova Viktoria Viktorovna

Cand. Agr. Sci.

Head of Scientific-

Educational Sector

e-mail: KudryshovaVV@yandex.ru

Federal State

Budget Scientific Institution

"North-Caucasian Federal

Scientific Center of Horticulture,

Viticulture, Winemaking»,

Krasnodar, Russia

The article reveals the need to develop a computer program for the creation and control of the ampelocenoses production potential. This program is necessary for agricultural producers

\footnotetext{
${ }^{1}$ Исследование выполнено при финансовой поддержке РФФИ и администрации Краснодарского края в рамках научного проекта № 19-44-230021 p_a
} 
необходима сельхозтоваропроизводителям для принятия управленческих решений по созданию и эксплуатации ампелоценозов в целях обеспечения конкурентоспособности производимой продукции. Создание единого банка данных генетических ресурсов винограда и их качественных признаков, проявляемых в различных почвенно-климатических условиях зон возделывания, даст возможность оперативно подбирать оптимальный сортимент для всех $30 н$ возделывания культуры с учётом изменения климата, а также создавать новые высокоэффективные сортоформы, что представляет существенный интерес для научных учреждений.

Разрабатываемая компьютерная программа базируется на обширных научных знаниях, включающих данные о сортах, ресурсном агроэкологическом потенциале областей возделывания винограда, на основе системного подхода, в наибольшей степени обеспечивающего реализацию всей совокупности факторов в продукционном процессе, определяющих стабильность плодоношения, продуктивность и качество винограда. В результате исследований разработана системная архитектура прототипа программного обеспечения методов управления комплексной устойчивостью виноградных агроэкосистем для обеспечения максимальной реализуемости биологического потенциала и самовоспроизводства ампелоценозов в условиях техногенной интенсификации производства и изменения климата. Представлены результаты исследований по разработке базы данных хозяйственно ценных признаков сортов винограда различного эколого-географического происхождения, включающей описание более чем по 80 признакам, и ресурсного агроэкологического потенциала областей возделывания винограда более чем по 20 параметрам по созданию моделей базовых (закладка нового виноградника) и оперативных (система ухода за действующим виноградником) технологий возделывания. to make the control decisions on the creation and operation of ampelocenoses in order to ensure the competitiveness of produced products. The creation of united database of grape genetic resources and their quality indicators, manifested in the different soil and climatic conditions of the cultivation zones, will make it possible to quickly select the optimal assortment for all crop cultivation zones taking into account climate change, as well as to create the new highly effective variety forms, which is of significant interest for scientific institutions. The computer program being developed is based on spacious scientific knowledge, including data on varieties, the resource agroecological potential of grape growing regions, based on a systematic approach that provides the greatest degree of realization of the factors totality in the production process that determine the stability of fruiting, productivity and quality of grapes. As a result of the research, a system architecture was developed for the prototype of software methods to manage the integrated stability of grape agroecosystems to ensure maximum feasibility of the biological potential and self-reproduction of ampelocenoses under the conditions of technogenic intensification of production and climate change. The results of studies on the development of a database of economically valuable traits of various ecological and geographical origin grape varieties are presented, including a description of more than 80 traits and resource agroecological potential of grape cultivation areas in more than of 20 parameters, as well as the creation of basic models (laying a new vineyard) and operational models (care system for the existing vineyard) for cultivation technologies. 
Ключевые слова: АМПЕЛОЦЕНОЗ, ПРОДУКЦИОННЫЙ ПОТЕНЦИАЛ, КОМПЛЕКСНАЯ УСТОЙЧИВОСТЬ, КОМПЬЮТЕРНАЯ МОДЕЛЬ, ПРОГРАММНОЕ ОБЕСПЕЧЕНИЕ
Key words: AMPELOCENOSIS, PRODUCTION POTENTIAL, INTEGRAITED STABILITY, COMPUTER MODEL, SOFTWARE

Введение. Задача совершенствования отечественного виноградарства вызвана необходимостью повышения его конкурентоспособности по основополагающим критериям: уровню реализации потенциала хозяйственной продуктивности, качеству винограда и винопродукции, экологической и эдафической устойчивости ампелоценозов, естественному процессу воспроизводства малого биологического круговорота и почвенного плодородия, экономической устойчивости виноградопроизводящих и перерабатывающих предприятий $[1,2]$.

В современной науке накоплен большой объем знаний, позволяющий решать актуальные проблемы отрасли виноградарства. Однако в силу разрозненности информации, отсутствия специальных механизмов её поиска и систематизации, она используется в ограниченном объёме.

Для эффективного применения накопленных знаний в организации современного производства винограда требуется разработка системных биоинформационных технологий управления ампелоценозами, учитывающих комплексное использование в продукционном процессе природных, биологических и антропогенных ресурсов, а также необходимых для полноценной оценки предлагаемых сортовых и технологических решений оцифрованных банков данных генетических ресурсов винограда и их соответствие различным почвенно-климатическим условиям среды обитания, сортовым технологиям и тенденциям изменения климата.

В связи с этим целью проводимых исследований является создание компьютерной программы для принятия управленческих решений, базирующейся на обширных данные о сортах (с учётом более 80-ти параметров, 
Плодоводство и виноградарство Юга России № 60(6), 2019 г.

при этом часть характеристик динамична в зависимости от места возделывания), ресурсном агроэкологическом потенциале областей возделывания винограда (более 20 параметров) и созданных ранее моделях расчёта базовых и оперативных технологий на основе мониторинга среды, диагностики и накопленной информации [3, 4].

Объекты и методы исследований. Объекты исследований - сорта винограда различного эколого-географического происхождения и природный ресурсный потенциал агротерриторий Краснодарского края. Исследования проводятся на основе комплексного подхода, характеризующегося использованием возможностей и методов информационных технологий, математического анализа, а также методов изучения механизмов формирования стабильности и продуктивности ампелоценозов. Методологическая база включает современные методы моделирования и информационных технологий [5-18].

Обсужнение результатов. Для разработки прототипа программы управления продуктивным потенциалом ампелоценозов, должен быть использован методический инструментарий по оптимизации параметров функциональной устойчивости воспроизводственных процессов по критериям рационального природопользования и ресурсосбережения, содержащий аналитический, конструкционный и математический аппараты с использованием статистической базы, программные пакеты прикладных программ по обработке информации [19-22]. Основным этапом создания программного продукта является разработка его системной архитектуры. Архитектура программы - это базовая организация системы, воплощённая в её компонентах, их отношениях между собой и с окружением, а также принципы, определяющие проектирование и развитие системы [23].

На этапе анализа требований к системе основное внимание должно уделяться определению конкретной информации, которую необходимо получать для управления продуктивностью ампелоценозов вне зависимости от 
того, как это сделать. С этой целью определён круг основных потребителейпользователей разрабатываемой программы:

- специализированные виноградопроизводящие хозяйства,

- винодельческие заводы,

- крестьянско-фермерские хозяйства,

- научные учреждения,

- министерства, департаменты сельского хозяйства и отраслевые управления,

- питомники и коммерческие компании, производящие посадочный материал винограда.

К информации, которую эти пользователи хотели бы получить, относятся (рис. 1):

- хозяйственно ценные характеристики сортов (физико-химический состав, органолептические показатели, сроки созревания, стабильность плодоношения и период созревания - для подбора сортимента, гарантирующего целесообразность, стабильность и экономический успех закладки виноградников, обеспечивающий равномерное поступление продукции в торговлю и на перерабатывающие предприятия (т.е. сортовой конвейер), донор устойчивости к различным болезням и вредителям - для создания новых сортов, обладающих устойчивостью к определённым заболеваниям и вредителям и т.д.);

- цифровые характеристики областей возделывания (почвенные и климатические, рельеф местности - для выявления наиболее подходящих для виноградников земель; климатические характеристики - для выбора сортимента, а также культуры ведения и др.);

- площади посадок различных сортов винограда и показатели их продуктивности (количественные и качественные) - для выявления наиболее благоприятных зон возделывания для конкретных сортов, исключения переизбытка конкретных сортов в сортименте региона (или области) и выявления недостающих сортов для создания сортового конвейера области; 
- базовые технологии возделывания - перечень рекомендаций, включая оптимизацию размещения сортов, подбор подвоев, формирование и ведение кустов, содержание и обработку почвы, режимы минерального питания, системы защиты растений винограда от вредных организмов на этапе закладки виноградников;

- оперативные технологии возделывания - перечень рекомендаций, включая обрезку лоз, нагрузку кустов глазками и урожаем, планируемую урожайность, оросительную норму, регламенты режимов питания и внесения минеральных удобрений, защиты растений от болезней и вредителей, экономическую целесообразность, контроль качества продукции и экологической безопасности агротерриторий на этапе вегетации виноградников;

- оценку эффективности действующих виноградников - для выявления причин низкого или недостаточно высокого уровня продуктивности и качества получаемого урожая, построения путей решения данной проблемы.

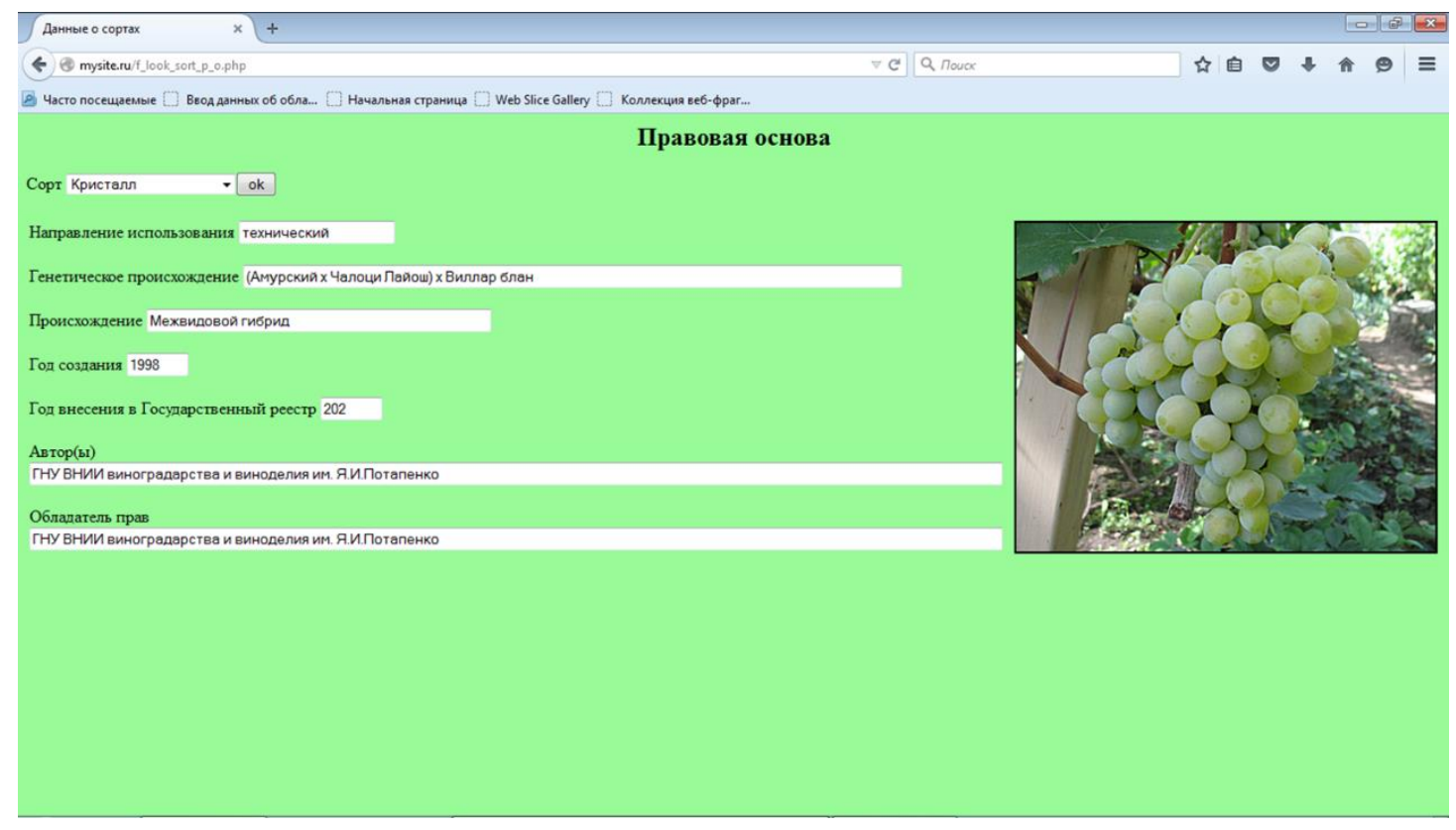

Рис. 1. Вид информации, выдаваемой программой, на примере данных о сорте винограда

Выявлены основные блоки, из которых должен состоять прототип разрабатываемого программного обеспечения, а именно: 
Плодоводство и виноградарство Юга России № 60(6), 2019 г.

- база данных сортов;

- база данных агроэкологических зон возделывания;

- база данных площадей посадок сортов (с данными об их урожайности и качестве урожая);

- СУБД (система управления базами данных);

- модули подбора сортов по заданным критериям;

- расчёт базовых технологий, оперативных технологий;

- оценка эффективности насаждений (с использованием самообучающихся систем), прогнозирования вспышек очагов болезней и вредителей;

- оценка природных потенциалов сельскохозяйственных зон Краснодарского края (с использованием методов ГИС).

Оценка природного потенциала сельскохозяйственных зон включает:

- базу данных виноградовинодельческих хозяйств;

- базу данных площадей посадок сортов винограда с разбивкой по хозяйствам (с данными об их урожайности и качестве урожая);

- базу данных погодно-климатических условий, включая метеорологические характеристики;

- базы данных почвенных условий и характеристик рельефа в разрезе всей области возделывания;

- базу данных экономико-географических характеристик территорий.

В разрабатываемой программе обобщены статистические данные об ампелографической коллекции, ресурсном потенциале областей возделывания и отдельных хозяйств. С помощью созданных моделей расчёта базовых и оперативных технологий на основе мониторинга среды, диагностики и накопленной информации она должна позволять генерировать рекомендации по управлению продуктивным потенциалом ампелоценозов (рис. 2). 


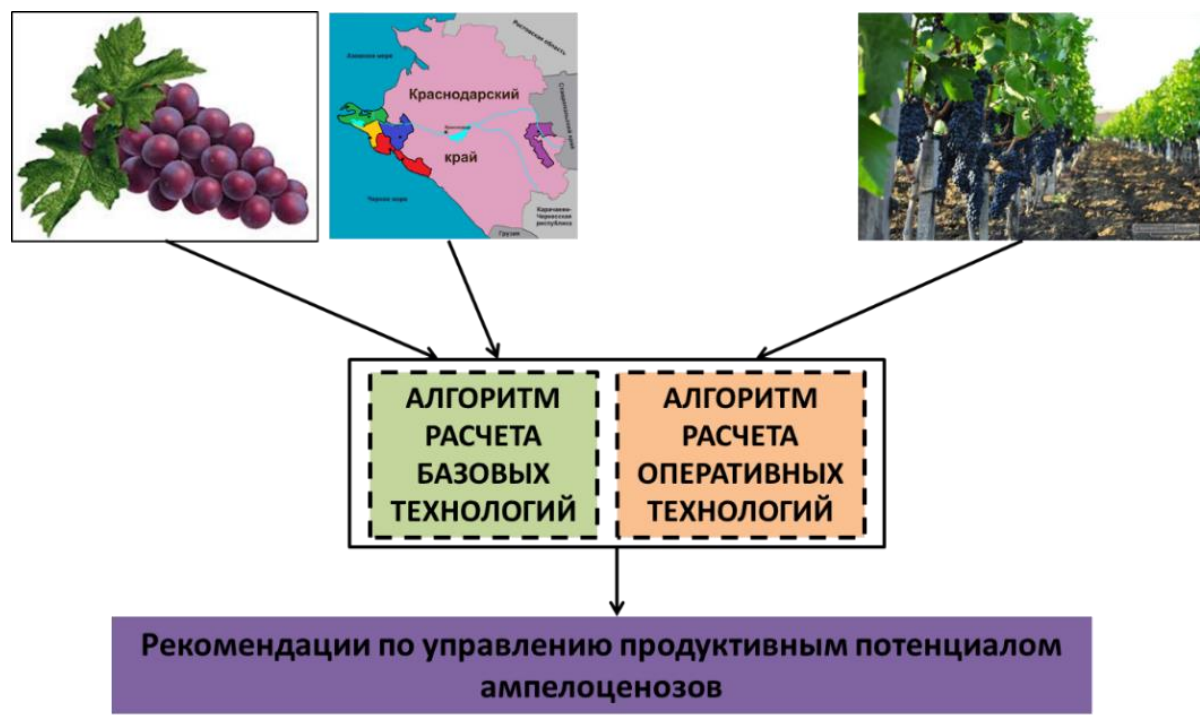

Рис. 2. «Архитектура» создаваемой компьютерной программы

Для определения требуемых характеристик сорта были проанализированы требования, предъявляемые различными пользователями к разрабатываемой системе, выявлены признаки, наиболее ёмко характеризующие сорт, а также показатели, характеризующие продуктивность, устойчивость, качество и другие хозяйственно ценные признаки. Все они структурированы по функциональным группам (рис. 3).

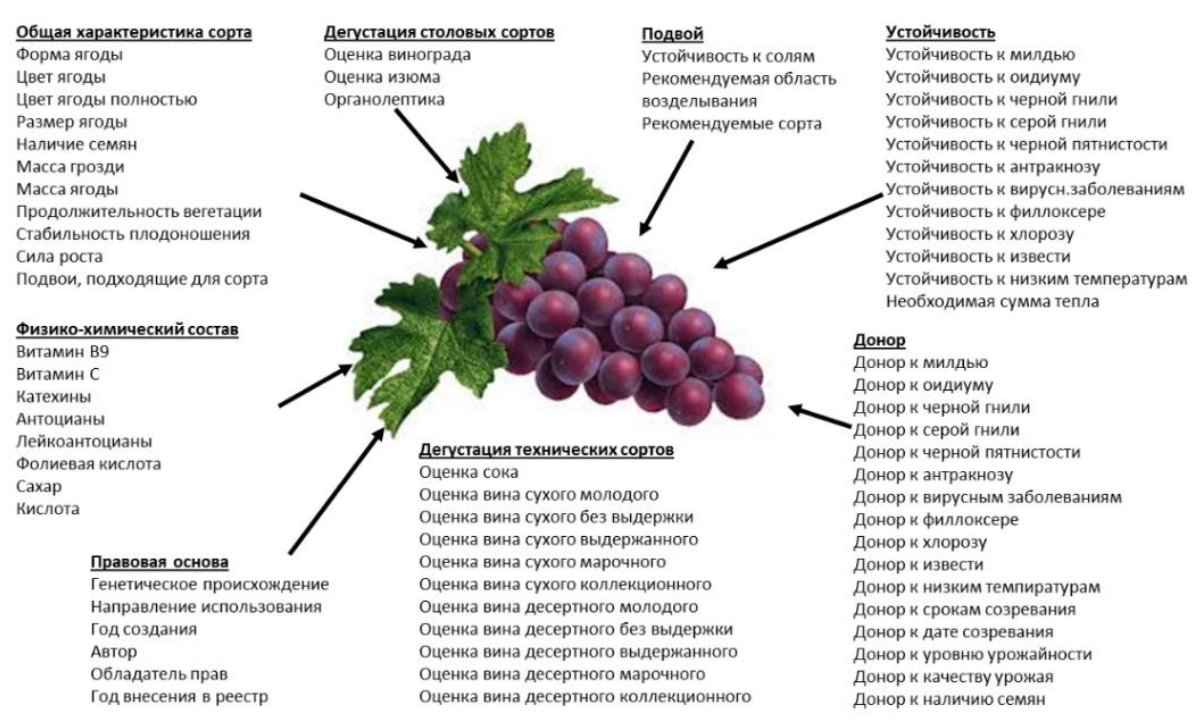

Рис. 3. Функциональные группы характеристики сортов винограда 
Плодоводство и виноградарство Юга России № 60(6), 2019 г.

На основании изучения биологических признаков сортов определены основные показатели, которые будут учитываться при создании моделей управления урожайностью винограда в определённых почвенно-климатических условиях посредством оптимизации их размещения.

Следующей задачей являлось изучение ресурсного потенциала областей возделывания и выявление факторов среды, влияющих на рост и развитие виноградного растения и реализацию его продукционного потенциала.

В качестве параметров, наиболее полно описывающих зоны возделывания, выбрано 25 характеристик. Следует отметить, что при изучении мировых доступных аналогов баз данных только в одной, наряду с данными о сортах, есть базы данных по характеристикам зон возделывания - это $L a$ Vigne et le vin (французская база данных). Она содержит информацию о 10 зонах возделывания, описание которых проводится 8 параметрами. Эти данные дают общее представление об описываемой области, но для проведения вычислений не эффективны.

Разрабатываемая база данных зон возделывания позволит пользователю получить не только общее представление о климате, расположении и прочих характеристиках исследуемых областей, но и будет использоваться при расчёте базовых (закладка нового виноградника) и оперативных (система ухода за действующим виноградником) технологий возделывания.

Отдельный блок разрабатываемой программы - это модули расчёта базовых и оперативных технологий возделывания. Базовые элементы технологий изначально закладывают основы эффективного, функционально направленного возделывания, стабильного плодоношения и высокого качества урожая. Они должны опираться на глубокие научные исследования и их апробацию.

В результате исследований разработан алгоритм базовых элементов технологий для создания эффективных ампелоценозов с учётом характери- 
стик сортов, подвоев, областей возделывания, почв и критериев их совместимости. Особое внимание уделено подбору подвоев, так как пара привойподвой подбирается единожды при закладке виноградника и не может быть изменена на всем протяжении его эксплуатации. На основании требований, предъявляемых к подвою, создан алгоритм оценки пригодности подвоев для конкретных сортов и областей возделывания.

Следующим этапом исследований являлось создание целостной математической модели управления продукционным потенциалом действующих ампелоценозов (оперативные технологии), то есть выбор из существующих моделей расчёта отдельных элементов технологий оптимальных (наиболее точно воспроизводящих объект моделирования) и создание комбинации этих моделей в единую систему уравнений взаимосвязанных переменных. Основной критерий выбора моделей - точность воспроизводства объекта моделирования (процесса, явления, закономерности и т.д.).

В ходе выполнения исследований изучено 20 моделей и методов расчёта основных элементов технологий возделывания (обрезка, нагрузка гроздями на куст, оросительная норма, режимы питания), выявлены наиболее точные, а также подходящие для использования в компьютерном моделировании, разработана модель расчёта системы защиты от болезней и вредителей.

Bыводы. Таким образом, на основе проведённых исследований разработана системная архитектура прототипа программы создания и управления продукционным потенциалом ампелоценозов: выбран оптимальный архитектурный шаблон, удовлетворяющий всем атрибутам качества, предъявляемым к системе; определён тип организации данных проектируемых баз данных. На основе анализа основного контингента потребителей создаваемого продукта разработан интерфейс главной страницы прототипа программы управления продуктивным потенциалом виноградников. 
Плодоводство и виноградарство Юга России № 60(6), 2019 г.

\section{Литература}

1. Петров В.С. Потенциал хозяйственной продуктивности винограда, его реализация в условиях умеренно континентального климата юга России // Магарач. Виноградарство и виноделие. 2016. № 1. С. 20-22.

2. Егоров Е.А., Воробьева Т.Н., Ветер Ю.А. Продуктивный потенциал промышленных виноградников // Аграрная наука. 2007. № 1. С. 18-21.

3. Анапская ампелографическая коллекция (биологические растительные ресурсы): монография / Егоров Е.А., Ильина И.А., Петров В.С., Панкин М.И., Ильницкая Е.Т., Талаш А.И., Лукьянов А.А., Лукьянова А.А., Коваленко А.Г., Большаков В.А., и др. Краснодар: ФГБНУ Северо-Кавказский федеральный научный центр садоводства, виноградарства, виноделия, 2018. 194 c. https://elibrary.ru/item.asp?id=36539666

4. Гвоздева Т.В., Баллод Б.А. Проектирование информационных систем. Ростовна-Дону: Феникс, 2009. 512 с.

5. Березюк, А.Т., Приходько, С.А. Выбор и конфигурирование комплекса технических средств информационной системы. Хабаровск, 2010. 122 с.

6. Бурмистров А.В., Белов Ю.С. Недостатки реляционных баз данных // Электронный журнал: наука, техника и образование. 2015. № 3 (3). С. 25-34.

7. Драч В.Е., Родионов А.В., Чухраева А.И. Выбор системы управления базами данных для информационной системы промышленного предприятия // Электромагнитные волны и электронные системы. 2018. Т. 23. № 3. С. 71-80.

8. Петухов И.С. Алгоритм определения необходимых индексов для оптимизации запросов с соединением двух таблиц в СУБД MYSQL (INNODB) // Научный вестник ГосНИИ ГА. 2017. № 16. С. 98-107.

9. Панченко И. PostgreSQL: вчера, сегодня, завтра // Открытые системы. СУБД. 2015. № 3. C. 34-37.

10. MySQL. Справочник по языку / Компания MySQL AB. М.: Вильямс, 2005. 432 с.

11. Веллинг Л., Томсон Л. MySQL. Учебное пособие / Люк Веллинг, Лора Томсон. М.: Вильямс, 2005. 304 с.

12. Аткинсон Л., Сураски 3. РНР 5. Библиотека профессионала М.: Вильямс, 2006. $944 \mathrm{c}$.

13. Гутманс, Э., Баккен С., Ретанс Д. РНР 5. Профессиональное программирование. С.-Пб.: Символ-Плюс, 2006. 704 с.

14. Котеров Д. РНР 5. С.-Пб.: ВНV, 2004. 1120 с.

15. Конверс Т., Парк Дж., Морган К. PHP 5 и MySQL. Библия пользователя. PHP5. М.: Диалектика, 2008. 1216 с.

16. Ломов, A.Ю. Apache, Perl, MySQL: практика создания динамических сайтов. Самоучитель. С.-Пб: БХВ-Петербург, 2007. 368 с.

17. Дунаев, В. Сценарии для Web-сайта. PHP и JavaScript. С.-Пб.: БХВ-Петербург, 2006. - $576 \mathrm{c}$.

18. АЈАХ и РНР. Разработка динамических веб-приложений / Д. Кристиан, Б. Бринзаре, Ф. Черчез-Тоза, М. Бусика [и др.] С.-Пб.: Символ-Плюс, 2009. 336 с.

19. Скотт В. Эмблер, Прамодкумар Дж. Садаладж. Рефакторинг баз данных: эволюционное проектирование. М.: Вильямс, 2007. С. 368.

20. Томас Коннолли, Каролин Бегг. Базы данных. Проектирование, реализация и сопровождение. Теория и практика - 3-е изд. М.: «Вильямс», 2003. С. 1436.

21. К. Дж. Дейт Введение в системы баз данных. 8-е изд. М.: Вильямс, 2006. С. 1328.

22. Голицина О.Л., Максимов Н.В., Попов И.И. Базы данных: Учебное пособие. М.: ФОРУМ: ИНФРА-М, 2003. С.352.

23. Гвоздева Т.В., Баллод Б.А. Проектирование информационных систем. Ростовна-Дону: Феникс, 2009. 512 с. 


\section{References}

1. Petrov V.S. Potencial hozyajstvennoj produktivnosti vinograda, ego realizaciya $\mathrm{v}$ usloviyah umerenno kontinental'nogo klimata yuga Rossii // Magarach. Vinogradarstvo i vinodelie. 2016. № 1. S. 20-22.

2. Egorov E.A., Vorob'eva T.N., Veter Yu.A. Produktivnyj potencial promyshlennyh vinogradnikov // Agrarnaya nauka. 2007. №1. S. 18-21.

3. Anapskaya ampelograficheskaya kollekciya (biologicheskie rastitel'nye resursy): monografiya / Egorov E.A., Il'ina I.A., Petrov V.S., Pankin M.I., Il'nickaya E.T., Talash A.I., Luk'yanov A.A., Luk'yanova A.A., Kovalenko A.G., Bol'shakov V.A., i dr. Krasnodar: FGBNU Severo-Kavkazskij federal'nyj nauchnyj centr sadovodstva, vinogradarstva, vinodeliya, 2018. 194 s. https://elibrary.ru/item.asp?id=36539666

4. Gvozdeva T.V., Ballod B.A. Proektirovanie informacionnyh sistem. Rostov-naDonu: Feniks, 2009. 512 s.

5. Berezyuk, A.T., Prihod'ko, S.A. Vybor i konfigurirovanie kompleksa tekhnicheskih sredstv informacionnoj sistemy. Habarovsk, 2010. $122 \mathrm{~s}$.

6. Burmistrov A.V., Belov Yu.S. Nedostatki relyacionnyh baz dannyh // Elektronnyj zhurnal: nauka, tekhnika i obrazovanie. 2015. № 3 (3). S. 25-34.

7. Drach V.E., Rodionov A.V., Chuhraeva A.I. Vybor sistemy upravleniya bazami dannyh dlya informacionnoj sistemy promyshlennogo predpriyatiya // Elektromagnitnye volny i elektronnye sistemy. 2018. T. 23. № 3. S. 71-80.

8. Petuhov I.S. Algoritm opredeleniya neobhodimyh indeksov dlya optimizacii zaprosov s soedineniem dvuh tablic v SUBD MYSQL (INNODB) // Nauchnyj vestnik GosNII GA. 2017. № 16. S. 98-107.

9. Panchenko I. PostgreSQL: vchera, segodnya, zavtra // Otkrytye sistemy. SUBD. 2015. № 3. S. 34-37.

10. MySQL. Spravochnik po yazyku / Kompaniya MySQL AB. M.: Vil'yams, 2005. 432 s.

11. Velling L., Tomson L. MySQL. Uchebnoe posobie / Lyuk Velling, Lora Tomson. M.: Vil'yams, 2005. 304 s.

12. Atkinson L., Suraski Z. PHP 5. Biblioteka professionala M.: Vil'yams, 2006. 944 s.

13. Gutmans, E., Bakken S., Retans D. PHP 5. Professional'noe programmirovanie. S.-Pb.: Simvol-Plyus, 2006. 704 s.

14. Koterov D. PHP 5. S.-Pb.: BHV, 2004. 1120 s.

15. Konvers T., Park Dzh., Morgan K. PHP 5 i MySQL. Bibliya pol'zovatelya. PHP5. M.: Dialektika, 2008. 1216 s.

16. Lomov, A.Yu. Apache, Perl, MySQL: praktika sozdaniya dinamicheskih sajtov. Samouchitel'. S.-Pb: BHV-Peterburg, 2007. 368 s.

17. Dunaev, V. Scenarii dlya Web-sajta. PHP i JavaScript. S.-Pb.: BHV-Peterburg, 2006. $-576 \mathrm{~s}$.

18. AJAX i PHP. Razrabotka dinamicheskih veb-prilozhenij / D. Kristian, B. Brinzare, F. Cherchez-Toza, M. Busika [i dr.] S.-Pb.: Sim-vol-Plyus, 2009. 336 s.

19. Skott V. Embler, Pramodkumar Dzh. Sadaladzh. Refaktoring baz dannyh: evolyucionnoe proektirovanie. M.: Vil'yams, 2007. S. 368.

20. Tomas Konnolli, Karolin Begg. Bazy dannyh. Proektirovanie, realizaciya i soprovozhdenie. Teoriya i praktika - 3-e izd. M.: «Vil'yams», 2003. S. 1436.

21. K. Dzh. Dejt Vvedenie v sistemy baz dannyh. 8-e izd. M.: Vil'yams, 2006. S. 1328.

22. Golicina O.L., Maksimov N.V., Popov I.I. Bazy dannyh: Uchebnoe posobie. M.: FORUM: INFRA-M, 2003. S.352.

23. Gvozdeva T.V., Ballod B.A. Proektirovanie informacionnyh sistem. Rostov-naDonu: Feniks, 2009. 512 s. 